\title{
New records of an alien aphid species Tinocallis (Sappocallis) takachihoensis from countries in central and northern Europe (Hemiptera, Aphididae, Calaphidinae)
}

\author{
Mariusz Kanturski', Yerim Lee², Łukasz Depa'
}

I Department of Zoology, Faculty of Biology and Environmental Protection, University of Silesia in Katowice, Bankowa 9, 40-007 Katowice, Poland 2 Laboratory of Insect Biosystematics, Department of Agricultural Biotechnology, Research Institute of Agriculture and Life Sciences, Seoul National University, Seoul, Republic of Korea

Corresponding author: Mariusz Kanturski (mariusz.kanturski@us.edu.pl)

Academic editor: R. Blackman | Received 13 October 2017 | Accepted 15 December 2017 | Published 17 January 2018

http://zoobank.org/9ADE43EA-A224-445B-8F78-C754059B1E11

Citation: Kanturski M, Lee Y, Depa $€$ (2018) New records of an alien aphid species Tinocallis (Sappocallis) takachihoensis from countries in central and northern Europe (Hemiptera, Aphididae, Calaphidinae). ZooKeys 730: 1-17. https://doi.org/10.3897/zookeys.730.21599

\begin{abstract}
The aphid genus Tinocallis Matsumura, 1919 (Hemiptera: Aphididae: Calaphidinae) in central and northern Europe is reviewed; it includes four species. The first records of the Asian elm aphid Tinocallis takachihoensis Higuchi, 1972 are reported from the Czech Republic, Denmark, and Poland. The record in Denmark is the first in Scandinavia. Alate viviparous females and nymphs of T. takachihoensis were collected from Ulmus glabra "Pendula" (the Czech Republic and Poland) and from U. minor (Denmark) in 2017. Tinocallis takachihoensis is the fourth Tinocallis species to be recorded from Poland and together with two other species from the subgenus Sappocallis, T. nevskyi and T. saltans, is a species of alien origin. The alate viviparous females are reviewed and re-described and their affinities and distribution in central and northern Europe are discussed. A key to the European species of Tinocallis based on the characters of live and slide-mounted specimens is also given.
\end{abstract}

\section{Keywords}

Aphidoidea, distribution, new record, Sternorrhyncha, Ulmus glabra 'Pendula'

Copyright Mariusz Kanturski et al. This is an open access article distributed under the terms of the Creative Commons Attribution License (CC BY 4.0), which permits unrestricted use, distribution, and reproduction in any medium, provided the original author and source are credited. 


\section{Introduction}

Of the approximately 1590 aphid species described or recorded from Europe (Nieto Nafría et al. 2013) to date, approximately 103 species are known to be of an alien origin from North America and Asia (Coeur d'acier et al. 2010, Pérez Hidalgo et al. 2011; Rakauskas 2011; Panini et al. 2017). The area of Poland is one of the best recognised in terms of aphid fauna in Europe with 766 recorded species and subspecies (Wojciechowski et al. 2015; Kanturski et al. 2017) to date. In Poland, as many as 34 species of an alien origin were reported earlier (Wieczorek 2011). However, this number is continuously changing due to ongoing research and biological invasions (Kanturski et al. 2017; Walczak et al. 2017).

The aphid genus Tinocallis Matsumura, 1919 (Calaphidinae) comprises 18-19 species within four subgenera (Favret 2017; Lee and Lee 2017) and is the second largest Panaphidini genus (Quednau 2001; Favret 2017). The species of this genus are characterised by a small and delicate body and are mostly associated with Ulmaceae (Blackman and Eastop 1994, 2017). All of the viviparae are alate and they usually have paired spinal and marginal tubercular processes on the thorax and abdomen. The secondary rhinaria on antennal segment III are narrow, transversely elongated, or slit-like. The genus has caused many taxonomical difficulties due to its seasonal variations (Quednau 2001).

The Asian elm aphid, Tinocallis takachihoensis Higuchi, 1972, is one of the members of the subgenus Sappocallis Matsumura, 1919. This species was originally described from Japan and is known to be primarily distributed in Eastern Asia (Higuchi 1972). Tinocallis takachihoensis along with T. saltans (Nevsky, 1929), T. ulmiparvifoliae Matsumura, 1919, and T. zelkowae (Takahashi, 1919) have been introduced to other parts of the world (Blackman and Eastop 2017; Foottit et al. 2006; Quednau and Shaposhnikov 1988). In Europe, this species was reported for the first time from France (from a suction trap) (Leclant 1986). Since then, this species has been reported from the United Kingdom (Döring 2007, 2008) and the Mediterranean area (Patti and Barbagallo 1997; Mier Durante and Perez Hidalgo 2002; Barbagallo and Massimino Cocuzza 2014). Although recent observations of the occurrence of this species come from Greece (Papapanagiotou et al. 2012), Germany, and the Netherlands (Piron 2013), Piron's information comes from a personal communication from Schrameyer who received the name of the species in question from Thieme (T. Thieme, pers. comm.).

In this paper, the occurrence of T. takachihoensis from the Czech Republic, Denmark, and Poland is reported for the first time. Its affinities to other known Tinocallis species from these regions are also discussed and a morphological key to the identification of all European representatives of this genus is provided.

\section{Material and methods}

Alate viviparous females and nymphs of Tinocallis takachihoensis were collected in Opava (the Czech Republic) on 19.08.2017, Katowice (Poland) on 12.07.2017, and Copenha- 
gen (Denmark) on 16.06.2017. The aphids were transferred to $80 \%$ ethanol and prepared after the Kanturski and Wieczorek (2012) protocol. In-life photographs were taken by the Sony SLT digital camera with the Sigma EX $50 \mathrm{~mm}$ lens with intermediate rings. Mounted specimens were examined by a Nikon Eclipse E600 and photographed by Nikon DS-Fi camera. The slides are deposited in the Aphidoidea collection of the Department of Zoology, University of Silesia in Katowice, Poland (UŚ).

The following abbreviations are used:

BL body length;

HW greatest head width across compound eyes;

ANT antennae or their lengths;

ANT I, II, III, IV, V, VI antennal segments I, II, III, IV, V, VI or their lengths (ratios between antennal segments are simply given as e.g. 'VI: III');

BASE basal part of last antennal segment or its length;

PT processus terminalis of last antennal segment or its length;

URS ultimate segments of rostrum (IV + V) or their length;

$\mathrm{Cu}_{1 \mathrm{a}} \quad$ first cubital vein;

$\mathrm{Cu}_{1 \mathrm{~b}} \quad$ second cubital vein;

FEMORA III hind femora length;

TIBIAE III hind tibiae length;

HT I first segment of hind tarsus,

HT II second segment of hind tarsus or its length;

SIPH siphunculi or their length.

For morphological comparison slides of Tinocallis specimens from other localities were used. The studied material is deposited in the Natural History Museum in London, UK (BMNH), and Zoological Institute, Polish Academy of Sciences, Warsaw, Poland (ZMPA).

\section{Taxonomy}

Genus Tinocallis Matsumura, 1919

Figs $1-8$

Tinocallis Matsumura, 1919: 100.

Lutaphis Shinji, 1924: 346.

Diagnosis. This genus can be recognized by having narrow transversely elongated or slit-like secondary rhinaria on ANT III, and ABD III, V, and VII with laterally displaced spinal dorsal setae. Abdominal tergites I and II usually have finger-like dorsal tubercles.

Type species. Tinocallis ulmiparvifoliae Matsumura, 1919. 


\section{Tinocallis (Sappocallis) takachihoensis Higuchi, 1972}

Figs 1-8; Table 1

Redescription. Alate viviparous female

Colour. Colour of live specimens: head and thorax black, ANT pale yellow with dark apices of segments, fore and middle legs pale yellow, hind legs pale yellow with black distal part of femora and proximal part of tibiae. Wings pigmented on the area of pterostigma, media and $\mathrm{Cu}_{1 \mathrm{~b}}$. Abdomen yellow (Fig. 1a, c). Pigmentation of mounted specimens: head and thorax brown (Fig. 1a). ANT pale with brown ANT I and ANT II and slightly darker apices of flagellar segments (Fig. 2a). Morphometric characters. ANT 0.76-1.00 $\times$ BL and 0.26-0.27 $\times$ HW. ANT III with 17-21 slit-like secondary rhinaria (Fig. 3a). PT 1.13-1.19 $\times$ BASE. Other antennal ratios: ANT VI/ANT III 0.57-0.64, ANT V/ANT III 0.52-0.54, ANT IV/ANT III 0.52-0.61. Ant I with 3 setae, Ant II with 2-3, ANT III with 9-13 setae, ANT IV with 2 setae, ANT V with 2-3 setae, ANT VI with one basal seta. URS $0.18 \times$ ANT III, $0.28-0.32 \times$ ANT VI, and 0.90-1.00 $\times$ HT II. Pronotum with two finger-like projections on the distal part (Fig. 4a). Mesonotum with two large, imbricated projections with rounded apices (Fig. 5a). HT II 0.18-0.20 × ANT III and 0.31-0.32 × ANT VI. Forewings with distal branches of media bordered with fuscous and with more-or-less extensive fuscous patches at distal ends of $\mathrm{Cu}_{1 \mathrm{a}}$ and $\mathrm{Cu}_{1 \mathrm{~b}}$ (Fig. 6a). Hind legs with dark distal part of femora and proximal part of tibiae (Fig. 7a). Abdomen pale, SIPH pale on basal part and pale brown on apex. Abdomen without sclerotisation besides very small darker projections on ABD III-V (Fig. 8a).

Material examined. Six alate viviparous females, CZECH REPUBLIC: Moravskoslezský kraj (Opava and vicinity), 18 Aug 2017, No. 08/17/5, on Ulmus glabra, coll. M. Kanturski (UŚ); five alate viviparous females, DENMARK: North East Zealand (Copenhagen), 18 Jun 2017, No. 05/17/3, on Ulmus sp., coll. M. Kanturski (UŚ); 15 alate viviparous females, POLAND: Upper Silesia (Katowice), 12 Jul 2017, No. 07/172b, on Ulmus glabra 'Pendula', coll. M. Kanturski (UŚ).

Additional material examined. six alate viviparous females, CHINA: Xiangshan Botanic Garden, 25 May1985, No. VFE18142, RLB3615, on Ulmus sp., coll. R. Blackmam \& V. Eastop $(\mathrm{BMNH})$; three alate viviparous females, UNITED KINGDOM: Humberside, 16 Oct 1997, No. BM1999-7 on Zelkova serrata, coll. not known $(\mathrm{BMNH})$.

\section{Tinocallis (Eotinocallis) platani (Kaltenbach, 1843)}

Figs 1-8; Table 1

Redescription. Alate viviparous female

Colour. Colour of live specimens: head and prothorax yellow with brown longitudinal stripes. The rest of thorax brown. ANT pale yellow with dark apices of segments, fore and middle legs pale yellow, hind legs with black femora and proximal part of 
Table I. Measurements (in mm) of alate viviparous females of Tinocallis species studied.

\begin{tabular}{l|c|c|c|c}
\hline Character & $\begin{array}{c}\text { T. takachihoensis } \\
\mathrm{n}=20\end{array}$ & $\begin{array}{c}\text { T. platani } \\
\mathrm{n}=13\end{array}$ & $\begin{array}{c}\text { T. saltans } \\
\mathrm{n}=9\end{array}$ & $\begin{array}{c}\text { T. } \text { nevskyi } \\
\mathrm{n}=15\end{array}$ \\
\hline BL & $1.27-1.47$ & $1.75-2.25$ & $1.50-1.75$ & $1.72-1.90$ \\
\hline HW & $0.39-0.46$ & $0.45-0.46$ & $0.40-0.45$ & $0.40-0.42$ \\
\hline ANT & $1.48-1.73$ & $1.65-1.77$ & $1.06-1.35$ & $1.34-1.48$ \\
\hline ANT III & $0.50-0.59$ & $0.60-0.70$ & $0.38-0.49$ & $0.45-0.47$ \\
\hline ANT IV & $0.26-0.36$ & $0.36-0.39$ & $0.21-2.28$ & $0.27-0.30$ \\
\hline ANT V & $0.27-0.31$ & $0.31-0.32$ & $0.17-0.22$ & $0.22-0.28$ \\
\hline ANT VI & $0.32-0.34$ & $0.21-0.22$ & $0.19-0.23$ & $0.29-0.32$ \\
\hline BASE & 0.15 & $0.17-0.18$ & $0.10-0.12$ & 0.14 \\
\hline PT & $0.17-0.18$ & 0.04 & $0.09-0.11$ & $0.15-0.18$ \\
\hline URS & $0.09-0.11$ & $0.12-0.13$ & $0.05-0.06$ & 0.085 \\
\hline III FEMUR & $0.38-0.58$ & $0.48-0.58$ & $0.36-0.40$ & $0.43-0.45$ \\
\hline III TIBIA & $0.74-1.06$ & $1.00-1.20$ & $0.63-0.70$ & $0.74-0.79$ \\
\hline HT I & $0.03-0.04$ & $0.04-0.05$ & 0.03 & $0.02-0.03$ \\
\hline HT II & $0.10-0.11$ & $0.11-0.12$ & 0.10 & 0.09 \\
\hline Forewings & $1.82-2.50$ & $2.25-2.75$ & $1.75-2.00$ & $2.05-2.25$ \\
\hline Hind wings & $1.00-1.80$ & $1.37-1.75$ & $1.20-1.55$ & $1.25-1.37$ \\
\hline SIPH & $0.04-0.05$ & $0.07-0.10$ & $0.05-0.06$ & $0.03-0.04$ \\
\hline cauda length & $0.05-0.06$ & $0.07-0.08$ & 0.07 & 0.05 \\
\hline cauda width & $0.05-0.06$ & $0.06-0.08$ & $0.05-0.07$ & 0.06 \\
\hline genital plate length & $0.07-0.08$ & $0.09-0.10$ & $0.08-0.09$ & $0.07-0.08$ \\
\hline genital plate width & $0.12-0.15$ & $0.17-0.20$ & $0.11-0.12$ & $0.13-0.18$ \\
\hline
\end{tabular}

tibiae. Wings pigmented on the area of pterostigma, media and $\mathrm{Cu}_{1 b}$. Abdomen yellow with brown extensive spots on the dorsal side (Fig. 1b). Nymphs pale yellow (Fig. 1d). Pigmentation of mounted specimens: head and thorax brown. ANT pale with brown ANT I, ANT II and slightly darker apices of flagellar segments (Fig. 2b).

Morphometric characters. ANT 0.78-0.94 $\times$ BL and 0.25-0.27 $\times$ HW. ANT III with 16-26 slit-like secondary rhinaria (Fig. 3b). PT 0.23-0.25 × BASE. Other antennal ratios: ANT VI/ANT III 0.31-0.35, ANT V/ANT III 0.45-0.51, ANT IV/ANT III 0.55-0.60. Ant I with 3-4 setae, Ant II with 4, ANT III with 10-15 setae, ANT IV with 3-5 setae, ANT V with 2-4 setae, ANT VI with one basal seta. URS 0.18-0.20 $\times$ ANT III, $0.57 \times$ ANT VI, and 1.04-1.09 $\times$ HT II. Pronotum without projections. Only very small protuberances, similar to those on the head are visible (Fig. 4b). Mesonotum without projections (Fig. 5b). HT II 0.17-0.18 $\times$ ANT III and 0.52-0.55 $\times$ ANT VI. Forewings without a radial sector. Stigma and media strongly bordered with fuscous basally as well as distally, with a dark spot over $\mathrm{Cu}_{1 \mathrm{~b}}$ (Fig. 6b). Hind legs with uniformly dark brown femora and proximal part of tibiae (Fig. 7b). Abdomen robust, pale with brown more or less extensive dorsal sclerites or broken crossbars. SIPH dark brown (Fig. 8b).

Material examined. three alate viviparous females, GERMANY: Lehmen, 18 Aug 1936, No. BM1984-340, on Ulmus effusa (= U. laevis), coll. D. Hille Ris Lambers (BMNH); three alate viviparous females, POLAND: Piekary Śląskie, 19 May 2015, 

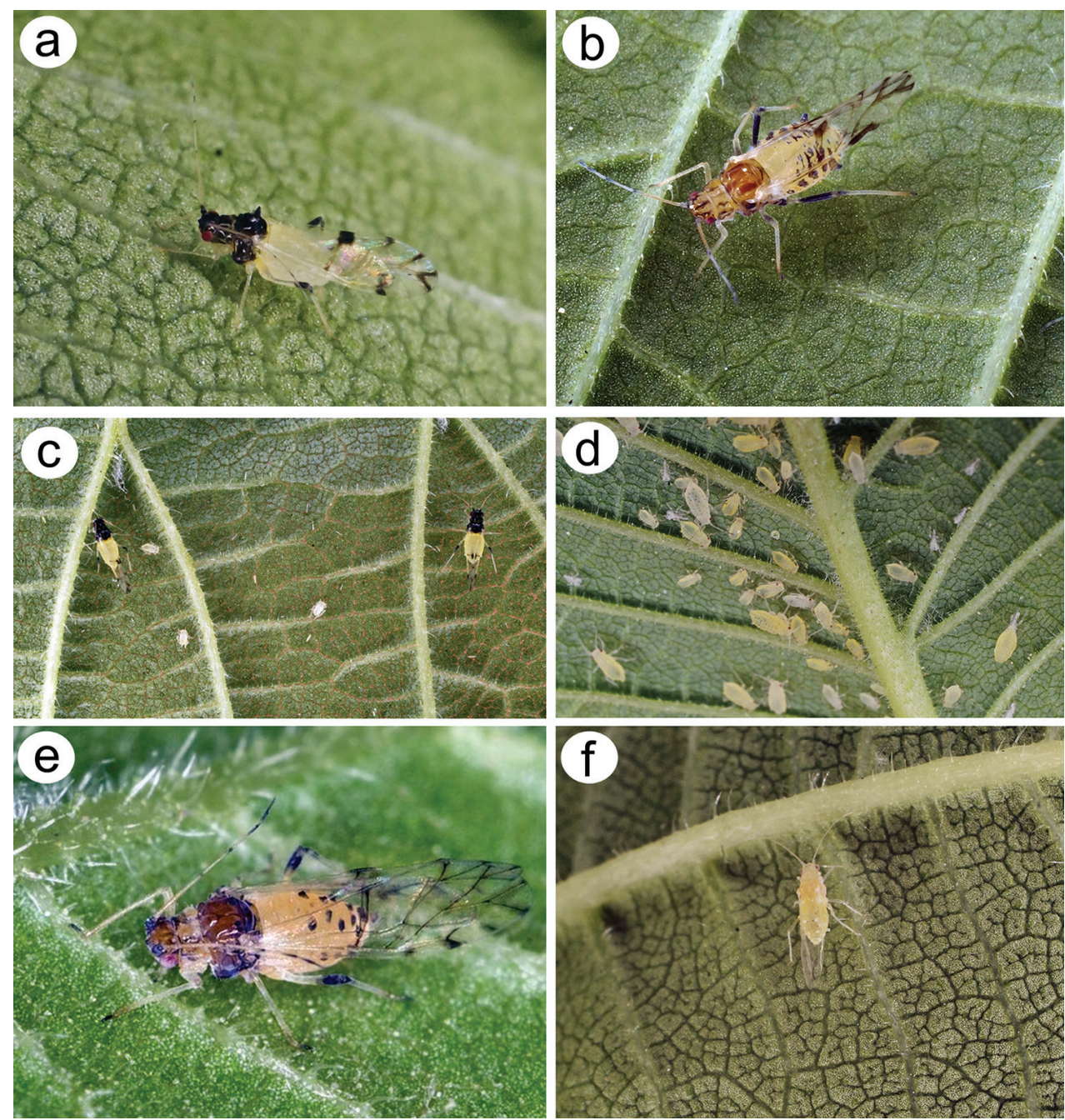

Figure I. Live specimens of a Tinocallis takachihoensis b T. platani $\mathbf{c}$ T. takachihoensis with first instar larvae $\mathbf{d}$ larvae and nymphs of T. platani $\mathbf{e}$ T. saltans $\mathbf{f} T$. nevskyi.

No. 04/15/33 on Ulmus sp., coll. M. Kanturski \& Ł. Depa (UŚ); three alate viviparous females, Warszawa, 13 May 1962, No. R3953, on Ulmus laevis, coll. H. Szelegiewicz (ZMPA); four alate viviparous females, UNITED KINGDOM: London, Kew, 29 Jun 1965, No. BM1982-492, on Ulmus laevis, coll. H.L.G Stroyan (BMNH).

Tinocallis (Sappocallis) saltans (Nevsky, 1929)

Figs 1-3; 5-8; Table 1

Redescription. Alate viviparous female. 

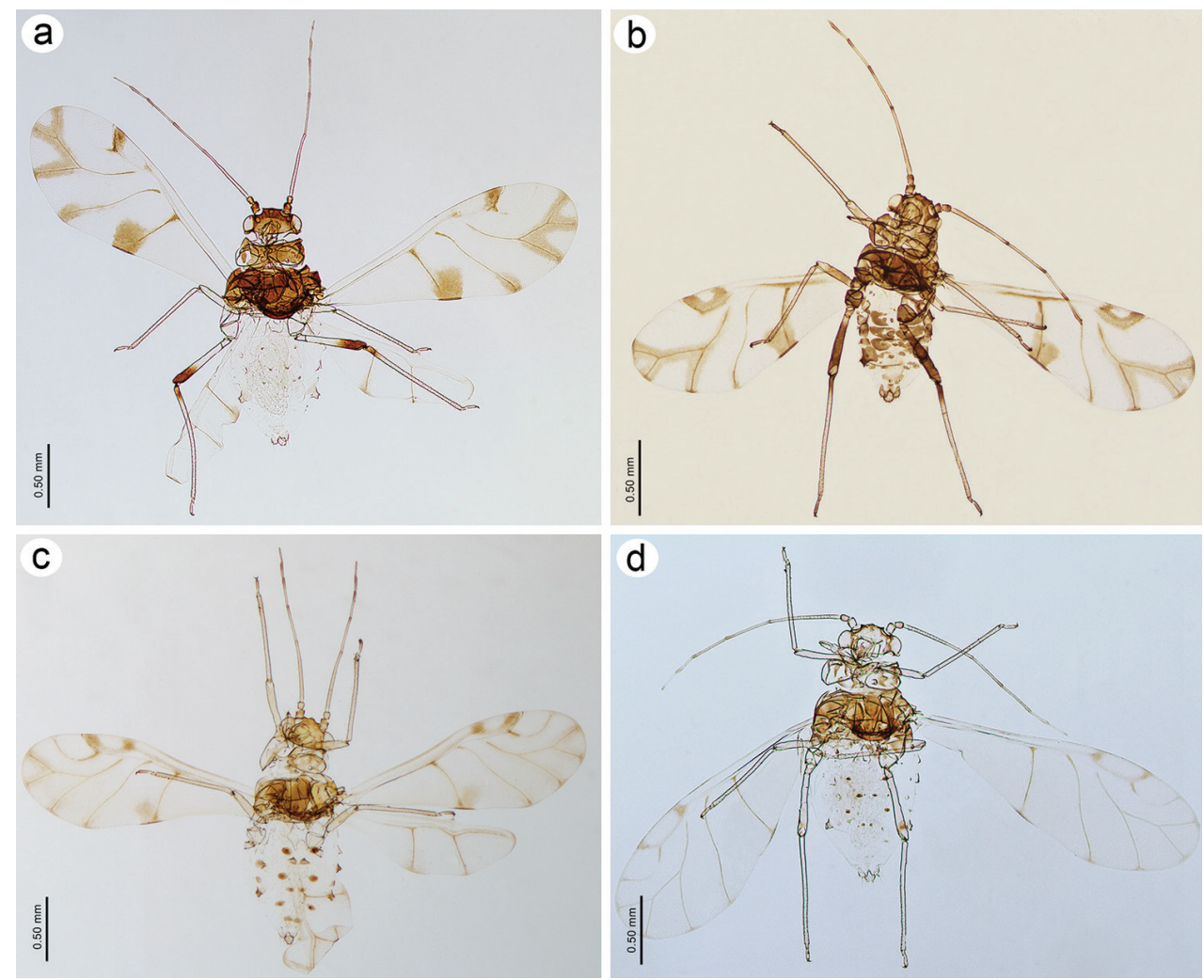

Figure 2. Mounted specimens of alate viviparous females of a Tinocallis takachihoensis $\mathbf{b}$ T. platani c T. saltans $\mathbf{d}$ T. nevskyi.

Colour. Colour of live specimens: head brown, ANT yellow with distinctly darker apices of ANT IV and V and almost whole ANT VI. Prothorax yellow or light brown, the rest of thorax dark brown to dark brown. Legs pale with visible darker distal part of hind femora. Abdomen yellow with brown with brown, small and rounded sclerites (Fig. 1e). Pigmentation of mounted specimens: head and thorax light brown to brown with lighter prothorax. The rest of body pale (Fig. 2c).

Morphometric characters. ANT 0.71-0.77 $\times$ BL and $0.33-0.37 \times \mathrm{HW}$. ANT III with 12-17 transverse oval secondary rhinaria (Fig. 3c). PT $0.95 \times$ BASE. Other antennal ratios: ANT VI/ANT III 0.47-0.51, ANT V/ANT III 0.44, ANT IV/ANT III 0.55-0.57. Ant I with 3 setae, Ant II with 2, ANT III with 10-11 setae, ANT IV with 2-4 setae, ANT V with 2 setae, ANT VI with one basal seta. URS 0.10-0.15 $\times$ ANT III, $0.21-0.30 \times$ ANT VI, and 0.50-0.60 $\times$ HT II. Pronotum with four projections, two on distal and two on proximal part (Fig. 4c). Mesonotum with two small, imbricated projections on the distal part with rounded apices (Fig. 5c). HT II 0.20-0.26 $\times$ ANT III and $0.42-0.51 \times$ ANT VI. Forewings with base of pterostigma with dark spot and pigmentation or bordering on branches of media and delicate light brown spot near $\mathrm{Cu}_{1 \mathrm{~b}}$ (Fig. 6c). Hind legs pale or light brown with darker distal part of femora 

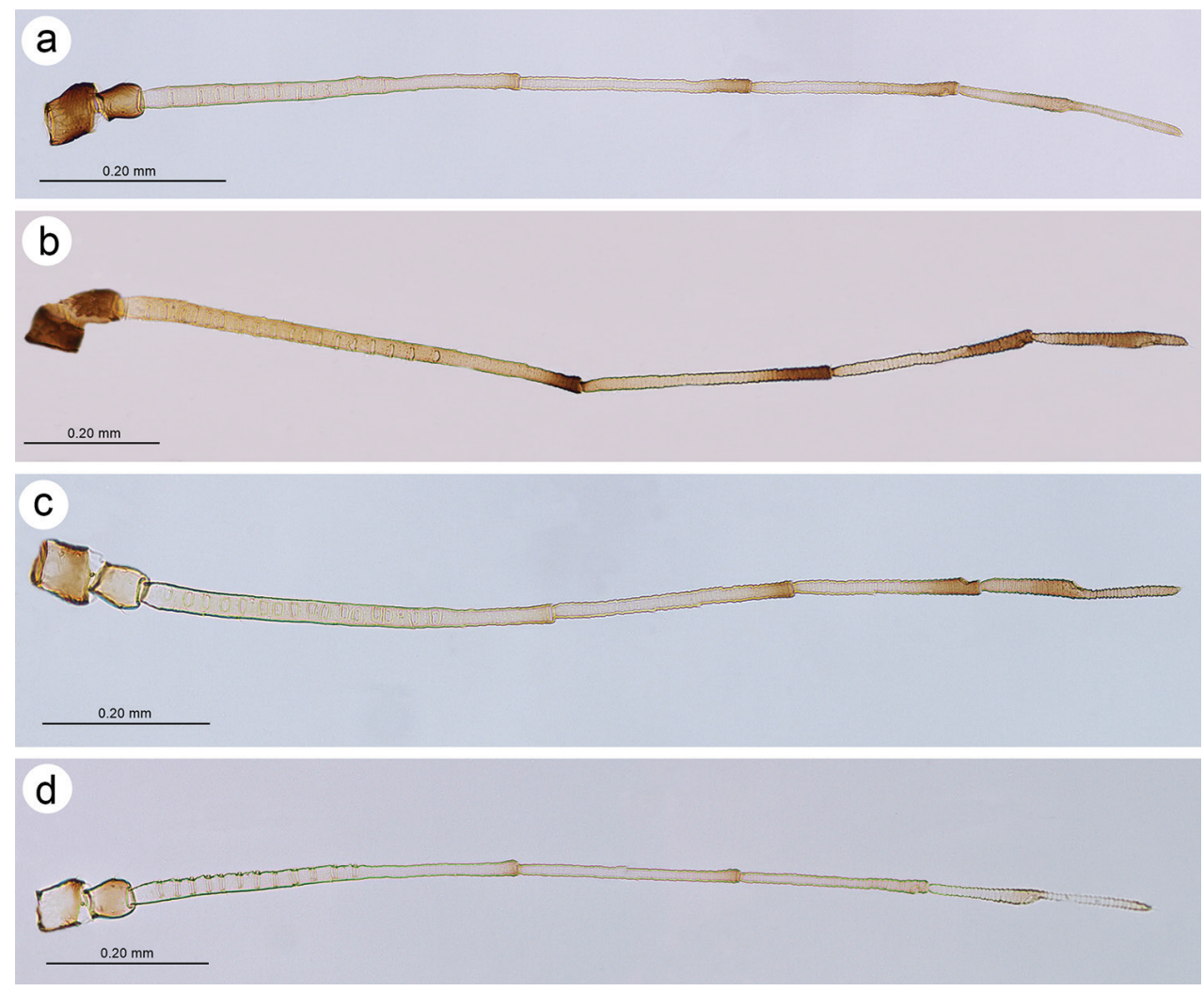

Figure 3. Antennae of alate viviparous females of a Tinocallis takachihoensis $\mathbf{b}$ T. platani $\mathbf{c}$ T. saltans d T. nevskyi.

(Fig. 7c). Abdomen pale with brown sclerites with distinct tubercles on ABD III-V. SIPH brown (Fig. 8c).

Material examined. three alate viviparous females, CHINA: Xiangshan, 25 May 1985, No. VFE 18128, on Ulmus sp., coll. V.F. Eastop (BMNH); two alate viviparous females POLAND: Katowice, 17 Jul 2016, No. 07/16/10, on Ulmus sp., coll. M. Kanturski leg., UŚ; two alate viviparous females, TAJIKISTAN: Gissarskij cgrebt $(1300 \mathrm{~m})$, 03 Jul 1959, No. R.3964, on Ulmus campestris, coll. M. Narzikulov (ZMPA); two alate viviparous females, UKRAINE: Kanevskij zapov., 17 Aug 1945, No. R.3961, on Ulmus sp., coll. V. Mamontova (ZMPA).

Tinocallis (Sappocallis) nevskyi Remaudière, Quednau \& Heie, 1988 Figs 1-8; Table 1

Redescription. Alate viviparous female

Colour. Colour of live specimens: whole body pale yellow to whitish yellow with poorly visible very small, brown abdominal sclerites. Wings not pigmented (Fig. 1f). 

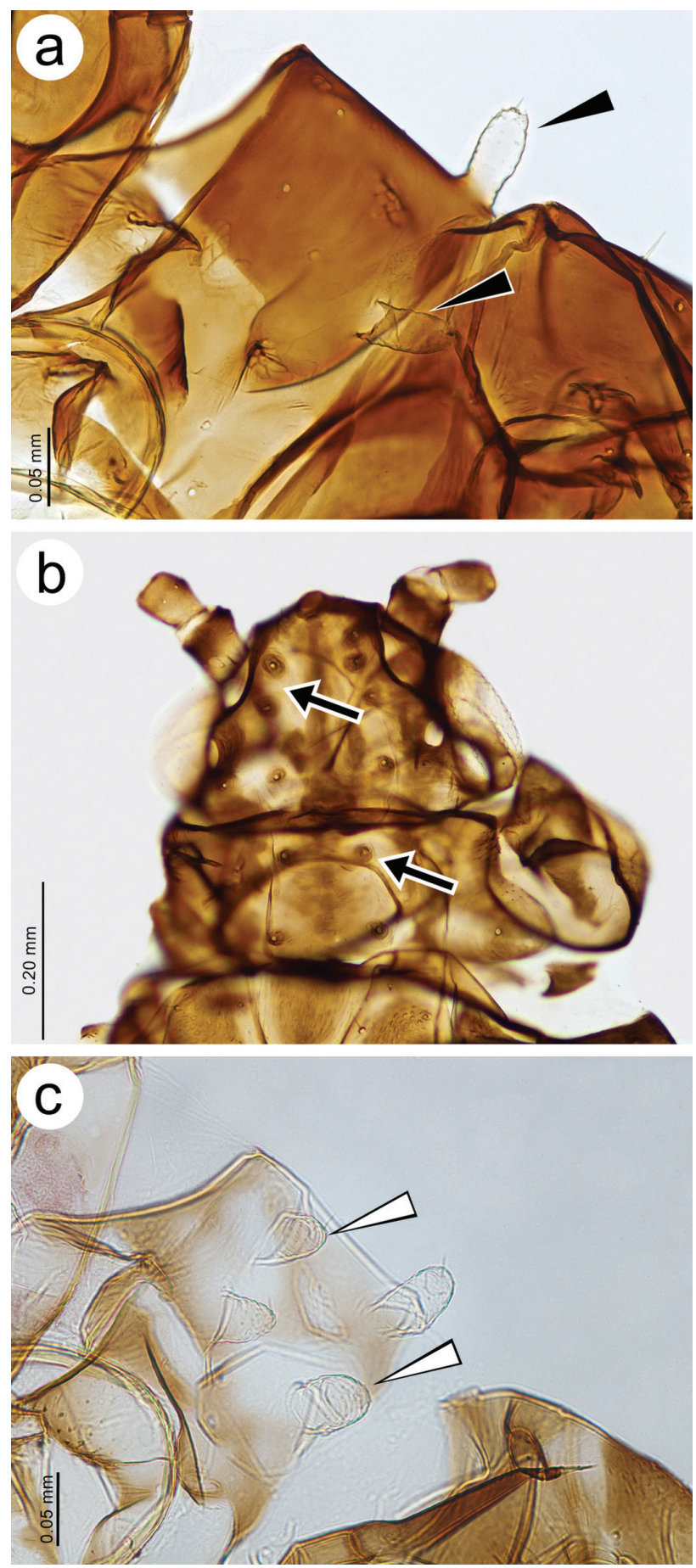

Figure 4. Head and pronotum features a pronotum of Tinocallis takachihoensis with one pair of projections (black arrowheads) b head and pronotum of T. platani without projections (arrows) c pronotum of T. nevskyi with two pairs of projections. 

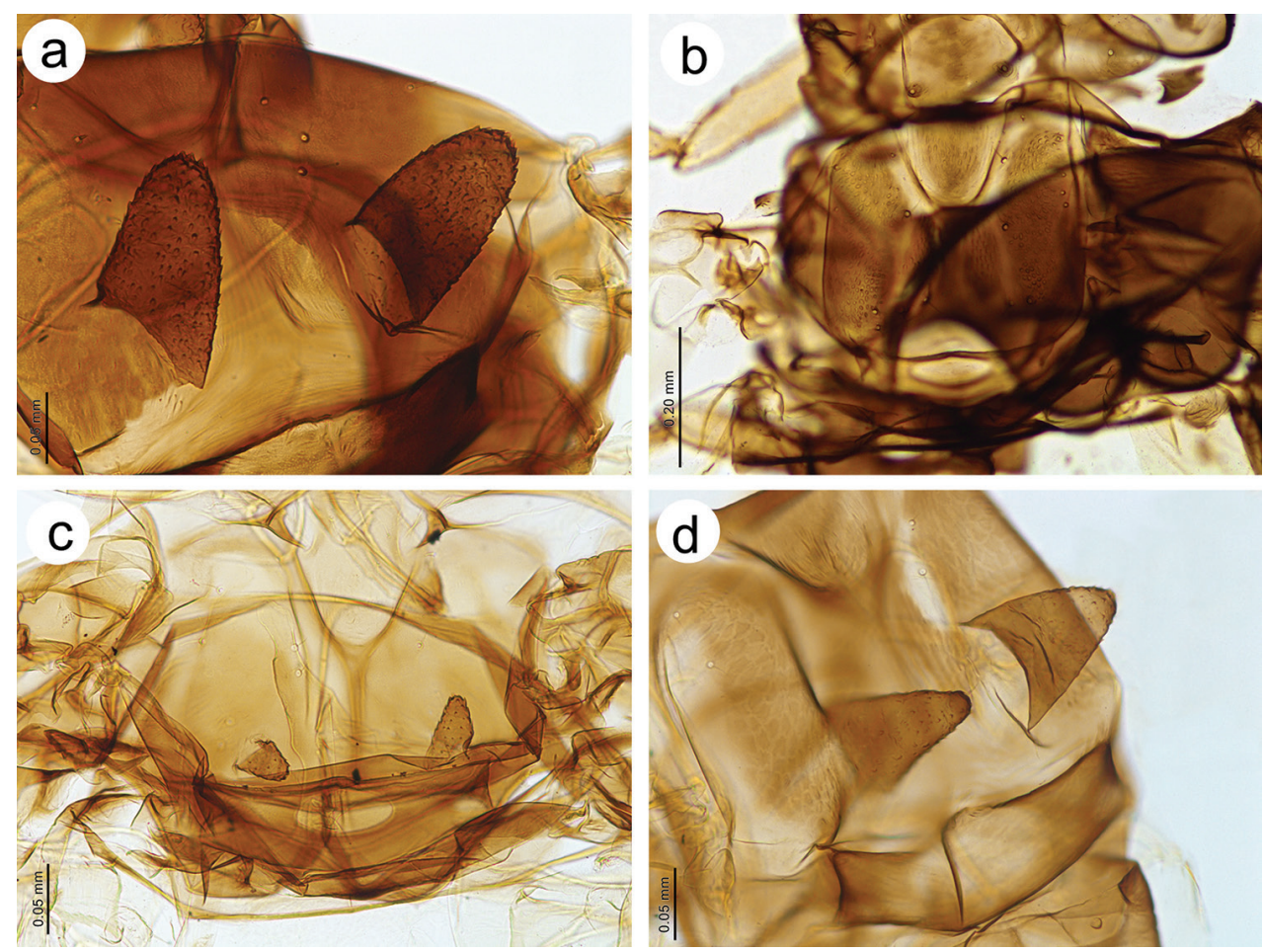

Figure 5. Mesonotum of a Tinocallis takachihoensis b $T$. platani (without projections) c T. saltans d T. nevskyi.

Pigmentation of mounted specimens: head pale with light brown edges, ANT pale, pronotum pale with light brown longitudinal stripes. The rest of thorax brown (Fig. $2 \mathrm{~d}$ ).

Morphometric characters. ANT $0.78 \times \mathrm{BL}$ and $0.28-0.29 \times \mathrm{HW}$. ANT III with 13-15 slit-like secondary rhinaria (Fig. 3d). PT 1.07-1.24 $\times$ BASE. Other antennal ratios: ANT VI/ANT III 0.64-0.69, ANT V/ANT III 0.50-0.59, ANT IV/ANT III 0.60-0.63. ANT I with 2-3 setae, ANT II with 2, ANT III with 7-10 setae, ANT IV with 2-3 setae, ANT V with 2-3 setae, ANT VI with one basal seta. URS $0.18 \times$ ANT III, 0.26-0.29 × ANT VI, and 0.09-0.94 $\times$ HT II. Pronotum with four projections, two on distal and two on proximal part (Fig. 4c). Mesonotum with two large and wide basally, imbricated projections on the distal part (Fig. 5d). HT II $0.20 \times$ ANT III and 0.29-0.31 $\times$ ANT VI. Forewings with apices of media and $\mathrm{Cu}_{1 \mathrm{a}}$ with very small, poorly visible spots (Fig. 6d). Hind legs pale with small dark spot on distal part of femora, but the end of femora also pale (Fig. 7d). Abdomen, pale with brown, very small dorsal sclerites on ABD III-VIII but those on ABD VII and VIII poorly visible. SIPH pale brown (Fig. 8d).

Material examined. three alate viviparous females, AFGHANISTAN: Kabul, 08 May 1975, No. BM 1984-340, on Ulmus sp., coll. R. van den Bosch (BMNH); four alate viviparous females, POLAND: Katowice (first record for Upper Silesia), 

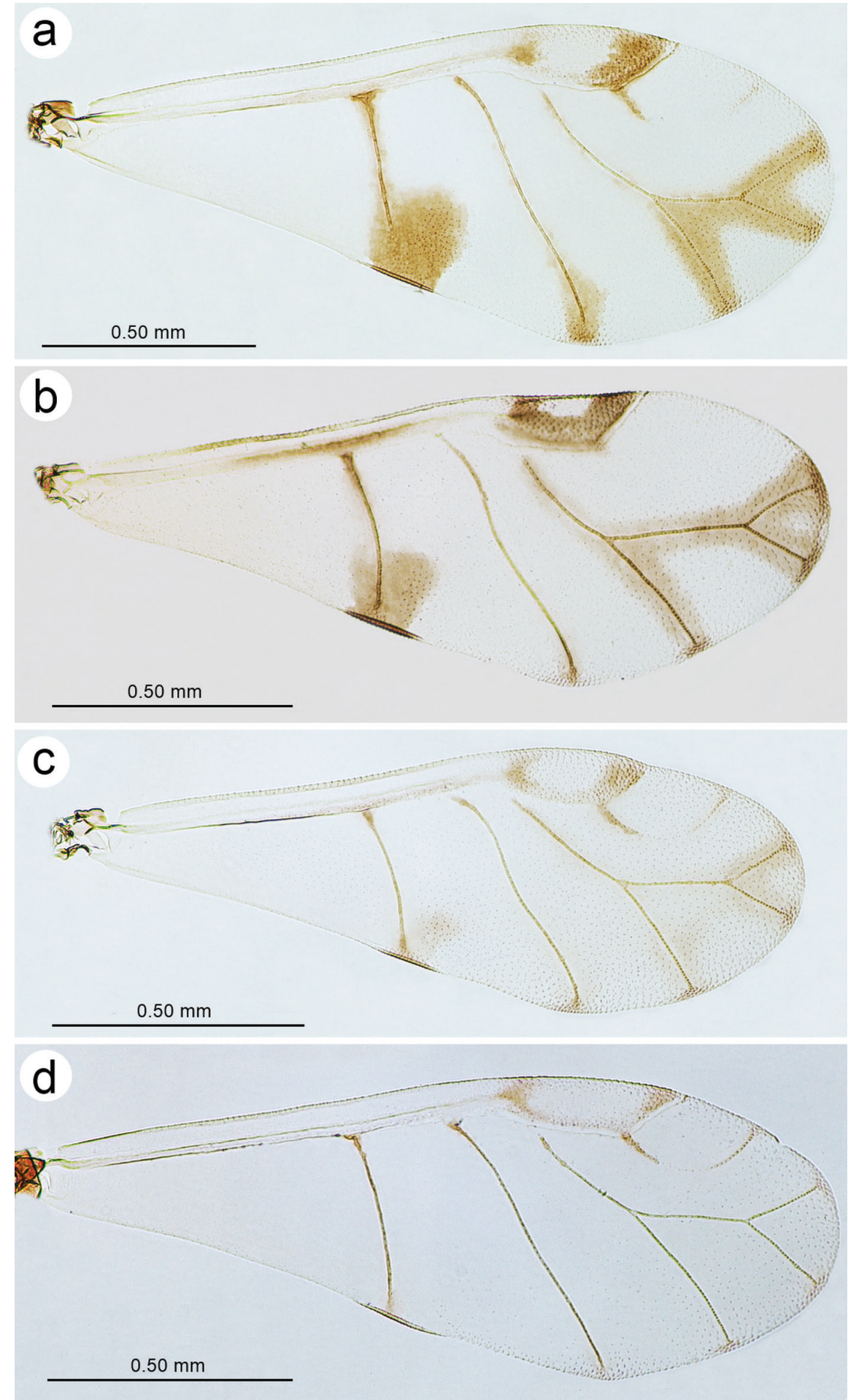

Figure 6. Forewing pigmentation of a Tinocallis takachihoensis b T. platani $\mathbf{c}$ T. saltans $\mathbf{d}$ T. nevskyi. 


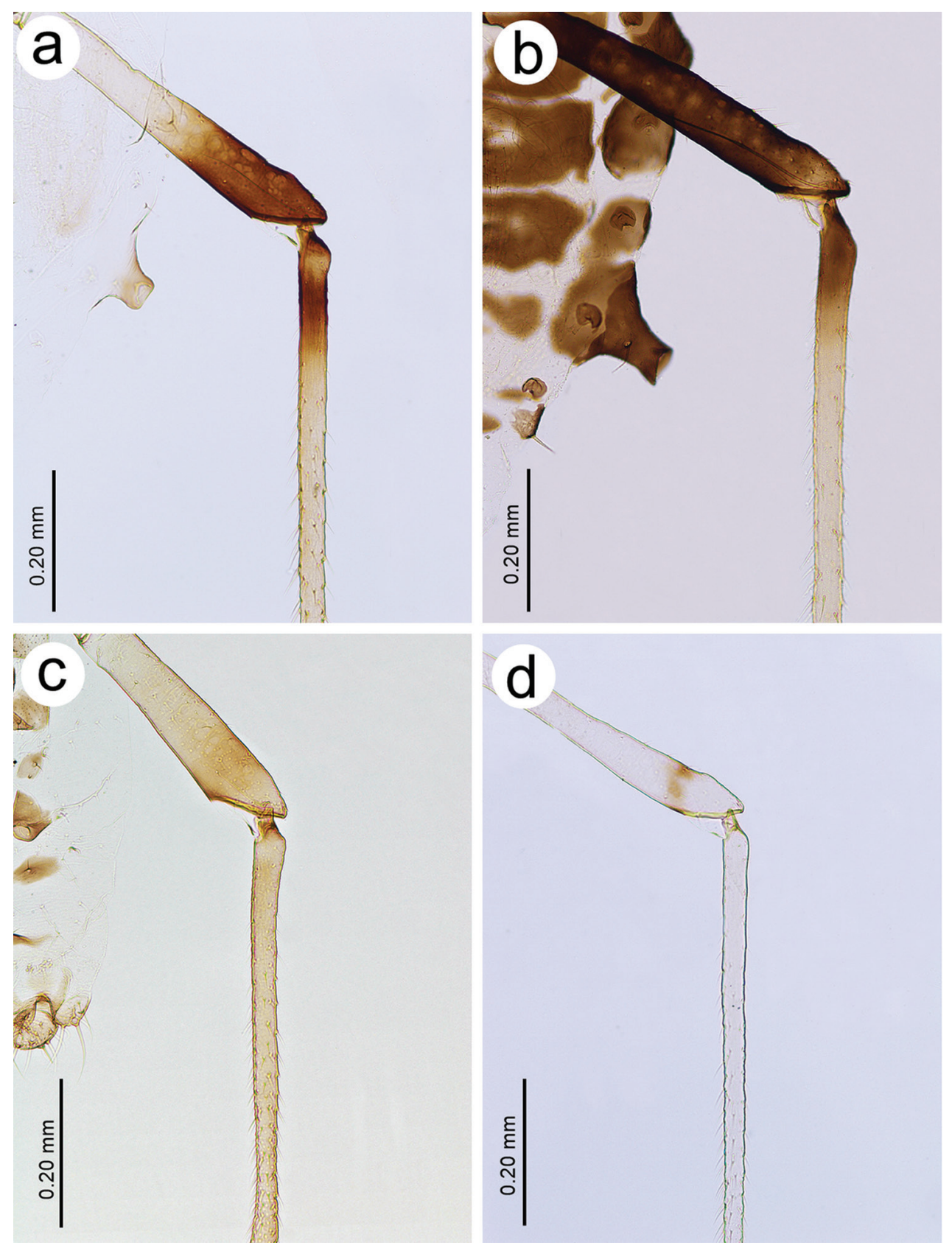

Figure 7. Hind leg pigmentation of a Tinocallis takachihoensis b T. platani c T. saltans $\mathbf{d}$ T. nevskyi.

12 Jul 2017, No. 07/17/2a, on Ulmus glabra 'Pendula', coll. Kanturski (UŚ); two alate viviparous females, SWEDEN: Lund, 03 Sep 1978, No. R.3963, on Ulmus glabra, coll. R. Danielsson (UŚ); six alate viviparous females, UNITED KINGDOM: ex culture of G. Hopkins, 04 Oct 1995, No. RLB 4337, on Ulmus sp., coll. R. Blackman (BMNH). 

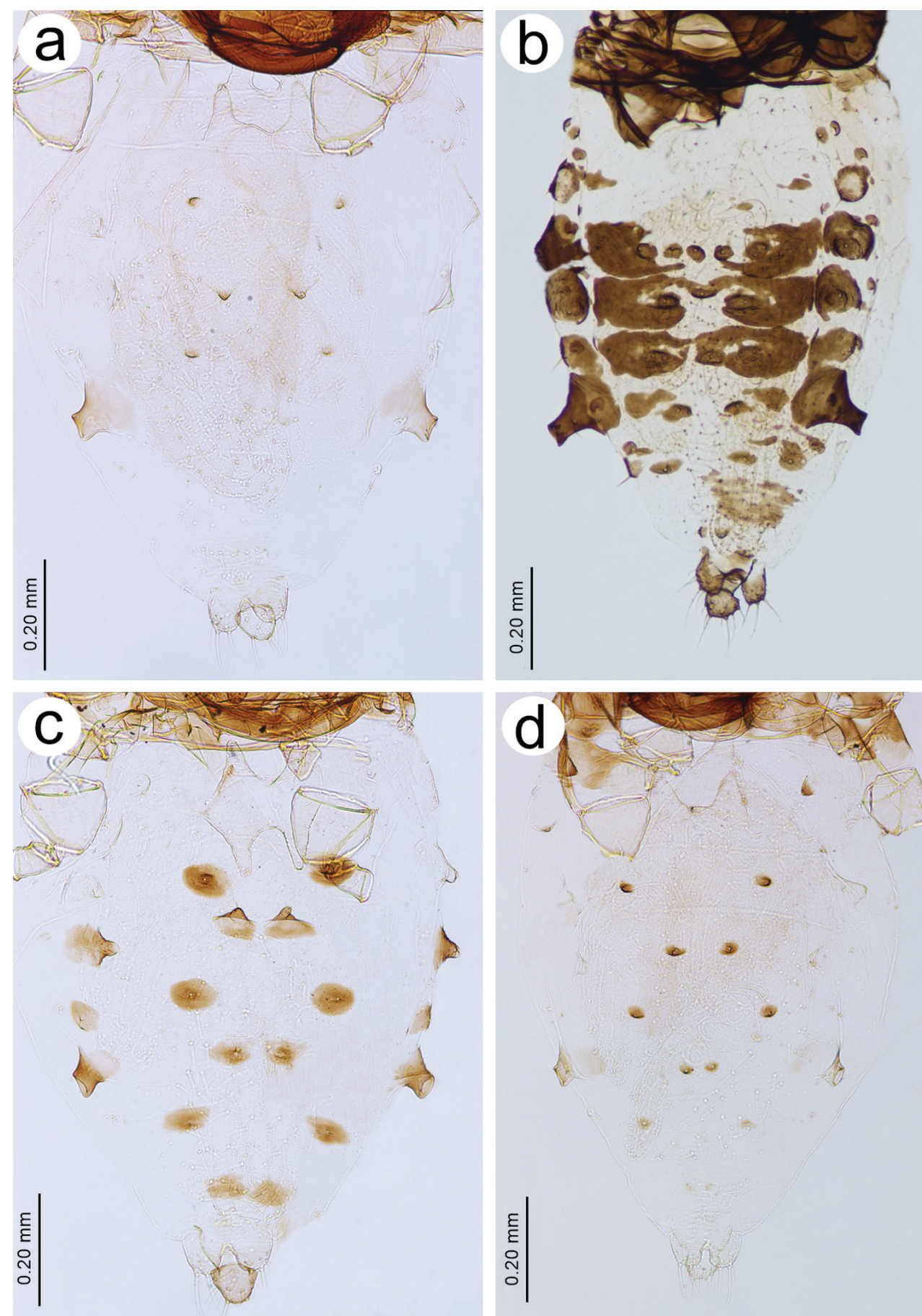

Figure 8. Abdominal sclerotization of Central and North European Tinocallis: a T. takachihoensis $\mathbf{b} T$. platani c T. saltans $\mathbf{d}$ T. nevskyi. 


\section{Key to the species of the genus Tinocallis in Europe}

1 Live specimens: head and thorax yellow or brown, abdomen yellow with or without brown patches. Mounted specimens: head and pronotum without projections (Fig. 4b). Mesonotum without projections. PT shorter than 0.50 $\times$ BASE

- $\quad$ Live specimens: head and thorax from yellow to dark. If brown to dark, then abdomen only with small circular sclerites and scleroites. Mounted specimens: pronotum with one or two pairs of finger-like projections (Figs. 4a, c). Mesonotum with one pair of projections. PT as long as or longer than $0.50 \times$ BASE

2 Live specimens: head and thorax brown, abdomen yellow with extensive brown patches (Fig. 1b). Mounted specimens: forewings pigmented, hind femora brown, abdomen with extensive, dark sclerotisation (Fig. 2b) .......... T. platani

- Live specimens: pale yellow without any patches. Mounted specimens: forewings not pigmented, hind femora pale, abdomen without dark sclerotisation

T. zelkowae

3 Live specimens: head and thorax black, abdomen yellow without dark sclerites (Fig. 1a, c). Pronotum with one pair of projections on distal part. Forewings pigmented. Hind legs with brown distal part of femora and proximal part of tibiae (Fig. 7a)

T. takachiboensis

- $\quad$ Live specimens: head and thorax greenish or yellow to brown, abdomen with small to large circular sclerites or marginal projections. Mounted specimens: pronotum with two pairs of projections on proximal and distal part. Forewings pigmented or not pigmented. Hind legs with pale femora only with a brown spot or band on the distal part and pale tibiae (Fig. 7c, d) ............... 4

4 Live specimens: greenish or bluish-green. Mounted specimens: Head with all projections prominent, the distal pair almost as long as the projections on the pronotum. Marginal projections on ABD II-IV almost as long as the spinal projections

T. ulmiparvifoliae

- $\quad$ Live specimens: yellow to brown. Mounted specimens: Head with small projections, the distal pair clearly shorter than projections on pronotum. Marginal projections on ABD II-IV clearly shorter than spinal projections .......5

5 Live specimens: head and thorax brown, abdomen with clearly visible sclerites with projections or tubercles, wings clearly pigmented (Fig. 1e). Mounted specimens: ANT III secondary rhinaria transverse oval (Fig. 3c). Wings clearly pigmented. Abdomen with small, sclerotised, spinal projections on $\mathrm{ABD}$ IV (Fig. 8c)

T. saltans

- $\quad$ Live specimens: head and thorax yellow or thorax brown with poorly visible sclerites, wings not pigmented. Mounted specimens: ANT III secondary rhinaria slit-like (Fig. 3d). Wings very poorly pigmented. Abdomen without small sclerotised spinal projections on ABD IV (with only two sclerites) (Fig. 8d) 


\section{Distribution comments}

Of the approximately 18 valid Tinocallis species, six are known from Europe (Blackman and Eastop 2017). Although Nieto Nafría et al. (2013) also include Sarucallis kahawaluokalani (Kirkaldy, 1906) as a representative of Tinocallis (in the subgenus Sarucallis), we follow the full generic status of Sarucallis (Quednau 2003). Two of the Tinocallis species known from Europe, T. ulmiparvifoliae and T. zelkowae, are only known from south-western Europe and on bonsai trees imported into the United Kingdom, while the remaining taxa have been reported to occur more widely, especially in central and northern Europe. From the four species presented here, T. platani is characterised as being widely distributed, $T$. nevskyi in the central, western, and northern parts of the continent, while T. saltans is recorded mostly in the central and eastern parts of Europe, but also from Italy and Spain (Nieto Nafría and Mier Durante 1998). Earliest European records of T. takachihoensis were from southern France and Italy, with more recent records from Greece, Germany, Malta, and the Netherlands. Thus, it seems from the dispersion routes of this species in Europe, that for more than a decade it has preferred regions with milder climate (the Mediterranean Basin and the western coast of Europe). Its sexual generation is as yet only known from Malta (Patti and Barbagallo 1997). The recent finding in Central Europe indicates the possibility of either the overwintering of this species in the climatic conditions of this part of Europe or rapid early-summer migrations from the territory that is already occupied (Piron 2013). Despite some milder winters, which have occurred in Central Europe recently and have influenced aphid biology (Depa et al. 2015), the period of aphid collection in this case (June-August) indicates the second possibility. The species, however, requires observation as it may become a pest on ornamental plants or it may adapt to more severe climatic conditions.

\section{Acknowledgements}

The first author is extremely grateful to Henrik Enghoff and Jan Pedersen (Natural History Museum of Denmark, University of Copenhagen, Denmark) for their kind help and support during his internship in the Museum. This research (DK-TAF 6818) received support from the SYNTHESYS Project, which is financed by the European Community Research Infrastructure Action under the FP7 "Capacities" Programme.

We would like to thank Thomas Thieme, Nicolás Pérez Hidalgo and Roger Blackman for all comments and suggestions that improved the first version of the manuscript.

\section{References}

Barbagallo S, Massimino Cocuzza GE (2014) A survey of the aphid fauna in the Italian regions of Latium and Campania. Redia XCVII: 19-47.

Blackman RL, Eastop VF (1994) Aphids on the Worlds Trees. An Identification and Information Guide. CAB International, Wallingford, 987 pp. 
Blackman RL, Eastop VF (2017) Aphids of the World's Plants: An Online Identification and Information Guide. http://www.aphidsonworldsplants.info [Accessed 25.08. 2017]

Coeur d'acier A, Pérez Hidalgo NP, Petrović-Obradović O (2010) Aphids (Hemiptera, Aphididae) Chapter 9.2. In: Roques A, Kenis M, Lees D, Lopez-Vaamonde W, Rabitsch W, Rasplus JY, Roy DB (Eds) Alien Terrestrial Arthropods of Europe BioRisk 4 (Special Issue): 435-474. https://doi.org/10.3897/biorisk.4.57

Depa Ł, Taszakowski A, Kanturski M (2015) Impact of warm weather events on prolongation of the life cycle of Stomaphis Walker (Hemiptera, Aphididae, Lachninae). Turkish Journal of Zoology 39: 669-671. https://doi.org/10.3906/zoo-1404-6

Döring TF (2007) Colonies of the Asian elm aphid Tinocallis takachihoensis Higuchi (Hemiptera: Aphididae) in Britain. The Entomologist's record and Journal of Variation 119(5): 226-227.

Döring TF (2008) Further sightings of the Asian elm aphid Tinocallis takachihoensis Higuchi (Hemiptera: Aphididae) in Britain. The Entomologist's record and Journal of Variation 120: 32 .

Favret C (2017) Aphid Species File. Version 5.0/5.0. http://Aphid.SpeciesFile.org [25.08.2017]

Foottit RG, Halbert SE, Miller GL, Maw E, Russell LM (2006) Adventive aphids (Hemiptera: Aphididae) of America north of Mexico. Proceedings of the Entomological Society of Washington 108: 583-610.

Higuchi H (1972) A taxonomic study the subfamily Callipterinae in Japan (Homoptera: Aphididae). Insecta Matsumura 35: 19-126.

Leclant F (1986) Cultures ornementales. Le puceron du Lagerstroemia, nouveau ravageur pour notre flore. Phytoma - Défense des cultures: 49-50.

Lee Y, Lee S (2017) A review of the Tinocallis Matsumura (Hemiptera: Aphididae) on the Korean peninsula, with description of one new species. Journal of Asia Pacific Entomology 23(3): 1019-1031. https://doi.org/10.1016/j.aspen.2017.07.005

Kanturski M, Wieczorek K (2012) Metody zbioru i preparowania mszyc (Hemiptera, Aphidoidea) w badaniach faunistycznych, taksonomicznych i molekularnych. Młodzi Naukowcy dla Polskiej Nauki 8(V): 137-143.

Kanturski M, Mruk K, Morawski M, Wojciechowski W, Depa Ł (2017) Nearctaphis bakeri (Cowen, 1895) and Illinoia liriodendri (Monell, 1879) - two aphid species (Hemiptera: Aphididae) of alien origin new to the Polish fauna. Annals of The Upper Silesian Museum in Bytom. Entomology 26 (online 002): 1-6.

Matsumura S (1919) New species and genera of Callipterinae (Aphididae) of Japan. Transactions of the Sapporo Natural History Society 7: 99-115.

Mier Durante MP, Pérez Hidalgo N (2002) Dos especies de Panaphidini (Hemiptera, Aphididae, Calaphidinae), propias de árboles ornamentales, introducidas en la Península Ibérica. Boletim da Sociedade Portugesa de Entomologia 157 (Supl. 6): 213-217.

Nieto Nafría JM, Mier Durante MP (1998) Hemiptera, Aphididae I. Fauna Iberica 11: 1-424.

Nieto Nafría JM, Andreev AV, Binazzi A, Mier Durante MP, Pérez Hidalgo N, Rakauskas R, Stekolshchikov A (2013) Fauna Europaea: Aphidoidea. Fauna Europaea version 2.6.2. www.faunaeur.org [accessed 25.08 2017]

Panini M, Massimino Cocuzza G, Dradi D, Chiesa O, Mazzoni E (2017) First report of Myzus mumecola (Matsumura, 1917) in Europe. Bulletin OEPP/EPPO Bulletin 47(1): 107-110. https://doi.org/10.1111/epp.12357 
Papapanagiotou AP, Nathanailidou M, Taylor M, Zarpas KD, Voudsouris K, Tsitsipis JA, Margaritopoulos JT (2012) New records of aphid species (Hemiptera: Aphididae) in Greece. Entomologia Hellenica 21: 54-68. https://doi.org/10.12681/eh.11518

Patti I, Barbagallo S (1997) Recenti acquisizioni faunistiche sugli Afidi della Sicilia. Bollettino del Laboratorio di Entomologia agraria Filippo Silvestri 53: 29-84.

Pérez Hidalgo N, Umaran A, Mier Durante MP (2011) First record of the adventive oriental aphid Schizaphis piricola (Matsumura, 1917) (Hemiptera, Aphididae) in Europe. ZooKeys 89: 49-56. https://doi.org/10.3897/zookeys.89.903

Piron PGM (2013) Appearance of Tinocallis takachihoensis (Homoptera: Aphididae) in The Netherlands. Entomologische berichten 73(6): 251-252.

Quednau FW (2001) World review of the genus Tinocallis (Hemiptera: Aphididae, Calaphidinae) with description of a new species. The Canadian Entomologist 133: 197-213. https:// doi.org/10.4039/Ent133197-2

Quednau FW (2003) Atlas of the Drepanosiphine aphids of the world part II: Panaphidini Oestlund, 1923-Panaphidina Oestrund, 1923 (Hemiptera: Aphidinae: Calaphidinae). The American Entomological Institute, Florida, 301 pp.

Quednau FW, Shaposhnikov GCh (1988) A list of Drepanosiphine aphids from the Soviet Far East, with descriptions of new species (Homoptera: Aphidoidea). The Canadian Entomologist 120(11): 1017-1032. https://doi.org/10.4039/Ent1201017-11

Rakauskas R (2011) Aphid species (Hemiptera, Sternorrhyncha: Aphididae) alien and invasive to Lithuania. Aphids and other Hemipterous Insects 17: 21-27.

Shinji O (1924) New aphids from Morioka. Dobutsugaku 36: 343-373. [In Japanese]

Walczak U, Borowiak-Sobkowiak B, Wilkaniec B (2017) Tetraneura (Tetraneurella) nigriabdominalis (Hemiptera: Aphidoidea) - a species extending its range in Europe, and morphological comparison Tetraneura (Tetraneura) ulmi. Entomologica Fennica 28: 21-26.

Wieczorek K (2011) Aphid species alien to Poland (Hemiptera: Aphididae). Polish Journal of Entomology 80: 203-224. https://doi.org/10.2478/v10200-011-0015-2

Wojciechowski W, Depa Ł, Kanturski M, Węgierek P, Wieczorek K (2015) An annotated checklist of the Aphids (Hemiptera: Aphidomorpha) of Poland. Polish Journal of Entomology 84: 383-420. https://doi.org/10.1515/pjen-2015-0033 